\title{
Democratic institutions and the energy intensity of well-being: a cross-national study
}

Adam Mayer

\begin{abstract}
Background: Energy consumption is necessary for human well-being, yet the growth of energy consumption also contributes to climate change and a range of negative externalities. Thus, a key sustainability challenge is to efficiently use energy consumption to promote human well-being. This manuscript contributes to the growing literature on the ecological intensity of well-being (EIWB) by modeling the relationship between democratic institutions and the energy intensity of well-being.

Methods: We use international data to understand how democratic institutions - understood as a combination of elected legislature, elected executives, and democratic competition-impact the energy intensity of well-being. The energy intensity of well-being is an adjusted ratio of energy consumption and life expectancy. We combine randomintercept mixed-effect models with entropy balancing constraints to create covariate balance between democracies and non-democracies.
\end{abstract}

Results: Contrary to our expectations, we find that consistently null results suggesting that democracies do not leverage their energy consumption to improve well-being more effectively than other systems of government. Democracy and its subcomponents do not appear to improve, or reduce, the energy intensity of well-being.

Conclusions: Democracy does not appear to improve sustainability, operationalized as the energy intensity of well-being. On the other hand, democracies do not appear to do worse than non-democracies, suggesting democratization can spread without reducing sustainability.

Keywords: Democracy, Causal inference, Energy consumption, Sustainable development

\section{Background}

The advent of modern forms of energy production-such as the burning of fossil fuels like coal and oil-in tandem with other technological changes helped usher in a rapid increase in standard of living in many parts of the world [1]. Before the rise of industrialized energy production, life expectancy and many other indicators of well-being had remained stagnant throughout much of human history. Hence, the widespread growth in the production and consumption of energy-as well as contemporaneous changes like the decline in deaths due to contagious disease-has been a key contributor to improving worldwide living standards, economic development, and the general advance of civilization [2, 3].

Correspondence: adam.mayer@colostate.edu

Colorado State University, Fort Collins, CO, USA
Energy is widely recognized as a prerequisite to modern lifestyles, economic development, and human development [4-7]. However, scholars have expressed grave concerns about the long-run sustainability of rapid population growth and rising quality of life since the work of Malthus [8] and Jevons [9].

While Malthus, Jevons, and more contemporary observers (e.g., [10, 11]) have focused primarily on issues of depletion and scarcity, it is important to note that rapid growth in energy usage has also engendered a range of negative externalities. Energy production, particularly from fossil fuels, has reduced air quality and threatened public health around the world. Public health impacts of energy production include reduced cognitive ability [12]-especially among children via low birth weight $[13,14]$-cancer $[15,16]$, asthma [17], and many 
other health maladies (e.g., $[18,19])$. Secondly, energy production often requires a large land footprint, reducing wildlife habitat, threatening biodiversity, and otherwise destroying culturally valued landscapes [20-22]. Indeed, in extreme situations, the quest for energy might render entire regions uninhabitable-infamous cases include Chernobyl and Centralia, Pennsylvania in the USA. Energy production and consumption, therefore, presents a paradox-it is both vital for human well-being while simultaneously a threat to human well-being. Hence, it is critically important to understand how well-being relates to energy consumption, and how energy might be used more efficiently to increase well-being.

The purpose of this paper is to extend the literature on the ecological intensity of human well-being (e.g., [23]) by considering the case and the energy intensity of well-being (hereafter "EIWB"). Below, we argue that this framework provides a unique perspective on how to capture the complex interplay between well-being and energy consumption crossnationally. We suggest that one potential contributor to cross-national variation in EIWB relates to political institutions-that is, we expect that democracies are able to leverage their energy consumption more effectively to improve human well-being.

This analysis makes several contributions to the literature. First, this is one of the few studies of the energy intensity of well-being (for exceptions, see [24] and [25]). Secondly, we rely on more nuanced indicators of democracy than much of the prior literature [26]. More significantly, we use novel counterfactual methods-in our case, an algorithmic approach called entropy balancing-to improve causal inference in the ecological intensity of human well-being literature.

\section{Literature review}

\section{Energy consumption and well-being}

Social scientists have long been interested in the relationship between well-being (broadly construed) and energy consumption, but despite long-standing interest, there are surprisingly few studies that have empirically documented this relationship. Generally, this research finds that energy consumption (or carbon emissions) is tightly linked to well-being at lower levels of economic development, often employing models informed by the IPAT or Kaya identity framework. However, for high-income nations, energy consumption and emissions tend to decouple from wellbeing such that growth in energy consumption does not necessarily improve well-being in high-income nations [4, 27-36]. Pasternak [33] refers to this phenomenon as a "plateau," while Martinez and Ebenhack [36] offer the term "saturation". While the estimates vary, the "saturation" point where additional energy consumption does not increase well-being appears to be startling low. Goldemberg et al. [37] suggests that this figure around $1 \mathrm{~kW}$ per capita can provide "basic needs," while Spreng [38] proposed a "2000-watt society". Steinberger and Roberts [39] argue that saturation point has changed over time, such that current technologies allow much greater wellbeing at low levels of energy consumption from the period of 1975 to 2005. They demonstrate that in 2005, about $40 \mathrm{GJ}$ or around $1 \mathrm{mt}$ of $\mathrm{CO}_{2}$ per capita can produce very high scores on many indicators of human development, such as life expectancy. Many other studies have pointed to the need to empirically assess the degree of environmental impacts-in the form of energy consumption, production, or emissions-necessary to sustain a decent standard of living $[7,40] .{ }^{1}$ Overall, the small body of prior literature strongly suggests that energy consumption far below that typical in developed nations can be sufficient to produce high levels of well-being.

\section{Ecological intensity of human well-being}

A related but distinct body of literature has considered the environmental efficiency of well-being, also referred to as the ecological intensity of well-being. Research in this tradition argues that it provides a useful operationalization of the notoriously elusive concept of "sustainability." In this tradition, sustainability is operationalized as the ratio of well-being to environmental degradation. In their foundational paper, Dietz, Rosa, and York [23] write:

"....it might be fruitful to investigate how nations differ in the amount of well-being they create for each unit of environmental stress they produce.

That is, it may be appropriate to move from looking just at environmental "bads" to looking at what "goods" nations manage to produce from stressing the environment." (pg. 116) [23].

Ecological intensity of well-being research is inspired by the concept of energy intensity, typically understood as the total energy consumption of a country divided by its gross domestic product. Ecological intensity of well-being departs from this approach by considering the ratio of country-level environmental impacts and some indicator of human well-being-such as life expectancy. For instance, [41] and [42] operationalize ecological intensity of wellbeing by using ecological footprints and life expectancy, [43, 44] and [45] employ carbon dioxide emissions per capita and life expectancy, while [24] and [25] rely on the ratio of energy consumption and life expectancy. On the other hand, [46] prefer to use the ratio of ecological footprints and average life satisfaction-an indicator of subjective well-being. 
Though the measurements vary, ecological intensity of well-being indicators is advantageous over other methods of operationalizing sustainability. More common methods of quantifying sustainability rely on single or composite measures of environmental impact, emissions, pollution, or ecosystem damage-such as the ecological footprints [47] or greenhouse gas emissions [48]. However, given that human well-being is coupled with natural systems in complex ways [49-51], an alternative approach to conceptualizing sustainability focusses on how humans can flourish with minimal ecological impact [23]. This approach is especially apt for energy consumption because, as we noted in the introduction, energy consumption both reduces human well-being via negative externalities while it also forms the bedrock for human flourishing. Thus, understanding how to minimize energy consumption while maximizing wellbeing is a critical question. In the next section, we review the literature on political institutions and the environment, focusing on the role of democracy in explaining crossnational variation in environmental outcomes.

\section{Political institutions and sustainability}

The relationship between political institutions-particularly democracy and democratization-and environmental outcomes at the national level has been given considerable attention by scholars over the last half-century. Indeed, in their widely cited review, Rosa and Dietz [52] identify institutions as a key driver of national greenhouse gas emissions. This diverse, multi-disciplinary collection of studies is informed by different theoretical perspectives. Typically, political scientists and economists have favored a perspective that alludes to rational choice arguments or arguments whose core notions parallels ecological modernization theory. Briefly, these viewpoints tend to suggest that democratization should improve environmental quality. Rational choice perspectives focus on the incentives faced by democracies. In democracies, citizens might express their preferences for environmental quality via voting while dictators have short time horizons and are often reliant on natural resources to bolster their tenuous grip on power $[53,54]$. Further, dictators might encourage rapid natural resource development, particularly resource extraction, to reward parties loyal to the regime $[55,56]$. While the details are not identical, ecological modernization theorists also view democracy as a positive for environmental quality, primarily because democracies can more effectively pursue "ecological rationalization" via carefully designed policy and lifestyle change [57-59]. Hence, significant theoretical perspectives suggest that, as democracies become more developed, resources should be used more efficiently and societies should become more sustainable.

The empirical literature paints a mixed picture, but overall, it seems to suggest that democracies fare better environmentally than dictatorships across a range of outcomes. Mather, Needle, and Fairburn [60] report that democracy reduces deforestation, and several studies have found that democracies tend to have lower carbon dioxide emissions [61-66]. Democracies also have lower sulfur dioxide emissions [67-69], tend to have cleaner water [65, 69], and improved biodiversity [70]. In contrast, other research has found that democracies have higher rates of deforestation [71-73] and lower water quality [74].

Most of these papers have relied upon a few different sources for indicators of democracy. These include the Polity2 variable from the Policy IV data $[75,76]$, the Freedom House indicators [72, 74], the indicators developed by the Economist magazine, or some combination [77]. This class of indicators is extremely useful, especially because they provide a single variable that summarizes institutional conditions within a given nation at a certain point in time. These indicators can provide relatively straightforward answers about the role of democracy (or lack thereof) in environmental problems.

However, their advantage is also their drawback. Nations with similar levels of democracy, as captured by indicators like Polity 2 or the Freedom House variables, can still exhibit substantial variation in terms of their system of government. That is, democracies are not equivalent across all institutional characteristics and the most popular indicators might miss some key nuances. To this end, Cheibub, Gandhi, and Vreeland [26] provide a novel set of indicators informed by a multi-faceted conceptualization of democracy. Drawing upon diverse theorizations of democracy, they argue that it has four primary features: (1) the chief executive (i.e., prime minister or president) must be popularly elected or appointed by an elected body, (2) the legislature must be popularly elected, (3) there must be multiple, competing political parties, and (4) incumbent chief executives must be replaced by elections governed by the same procedures by which they were initially elected. Below, we explain how these indicators were combined with causal inference methods for observational data to understand the relationship between democracy and EIWB.

\section{Methods \\ Dependent variable}

Our dependent variable is a ratio of energy use per capita (measured as a kilogram of oil equivalent) and life expectancy at birth in years, both variables were obtained from the World Bank database using the $d b$ worldbank Stata plug-in [78]. Using a ratio as a dependent variable creates a unique complication because the ratio can be dominated by either the numerator or denominator. The root of this problem is that the range and variation of both variables can differ quite markedly. Indeed, for the valid cases used 
in the models below life expectancy ranges from 41 to 83 with a standard deviation of 9 and a coefficient of variation of 0.12. Energy use per capita ranges from 59 to 22,762 with a standard deviation of 2533 and a coefficient of variation of 1 . Hence, there is much variation in both life expectancy and energy use per capita, but comparatively more variation in energy use. Energy use per capita, therefore, will inflate the variation in the ratio.

Fortunately, a widely accepted method has been developed to address this significant problem. The resolution involves equalizing the coefficient of variation for the numerator (in our case, energy use per capita) and coefficient of variation for the denominator (life expectancy) by adding a constant to the numerator, thereby shifting the mean without altering the variance $[24,41,43]$. For our variables, the coefficient of variation can be equalized to the fourth decimal place by adding 17,737 to energy use per capita. After performing this transformation, we multiply the ratio by 100 to facilitate more straightforward interpretation of our modeling results. This calculation be can expressed as:

$$
\begin{aligned}
\text { EIWB }= & {[(\text { Energy Consumption per capita }+17737)] } \\
& / \text { Life Expectancy } \times 100
\end{aligned}
$$

Figure 1 provides annual averages and interquartile range for our energy intensity of well-being (EIWB) variable from 1990 to 2008 , the period under analysis. Overall, EIWB has remained relatively stable over this period, though the trend seems to be towards reduced energy intensity of well-being.

\section{Binary treatments for democratic characteristics}

We constructed a series of binary variables to isolate different characteristics of democracy as defined in the

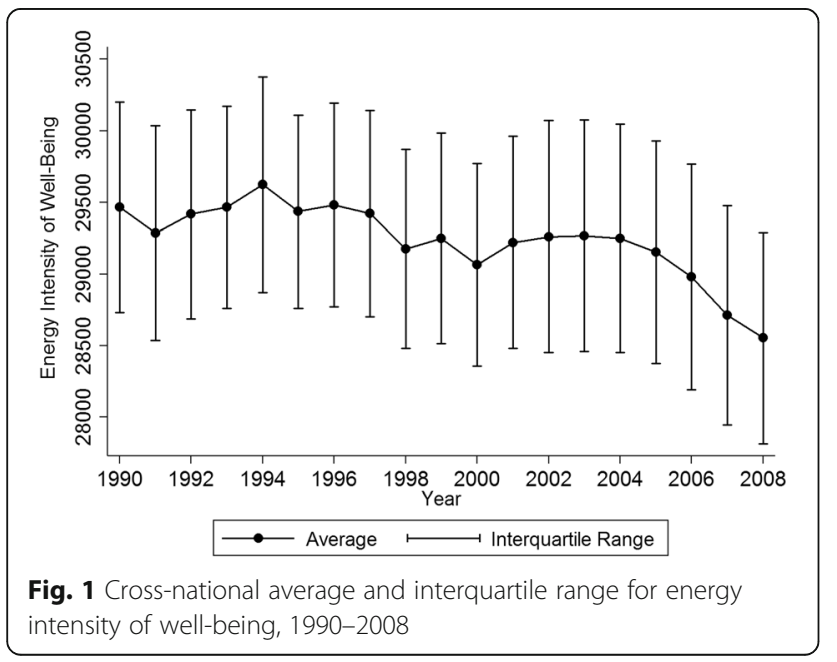

Democracy-Dictatorship dataset developed by [26]. For the sake of parsimony and to facilitate causal inference methods, we dichotomize several multiple-category indicators.

These include the exselec indicator for mode of executive selection. The original variable was scored with three categories for direct popular election, indirect election (i.e., selection of the executive by an elected assembly), and nonelected executive. This variable was transformed to isolate nations with elected executives $(0=$ non-elected legislature, $1=$ indirect or direct election). Next, we use a variable to identify nations with an elected legislature, recoded from the legselec variable in the original data. The recoded variable is scored such that countries without a legislature or with a non-elected legislature are coded with a "0" and nations with an elected legislature are coded with a " 1 ". Then, we used the defacto indicator to capture political competition. We group together nations with no parties or one party into the "0" category, and multiple parties are coded as a "1". Finally, we created a binary indicator for a "full" democracy where a given country has the combination of an elected executive, an elected legislature, and competing political parties.

\section{Control variables}

An array of factors has been demonstrated to influence national-level environmental outcomes. Chief among these is economic development, where studies consistently show that economic growth is associated with higher greenhouse gas emissions [79-82] and ecological footprints [83, 84]. Some, but not all, analyses find a non-linear relationship between economic development and ecological degradation whereby economic growth increases degradation for lowincome countries but improves environmental performance for high-income countries [85-88] —-this inverted U-shaped relationship has been dubbed the "environmental Kuznets curve." More specific to the ecological intensity of wellbeing, Dietz, Rosa, and York [41] find evidence against the environmental Kuznets curve. Operationalizing ecological intensity of well-being as the ratio of ecological footprints to life expectancy, the authors observe a U-shaped relationship between the ecological intensity of well-being and development. Here, we include GDP per capita in thousands of 2011 US dollars adjusted for purchasing power parity. ${ }^{2}$ In keeping with standard modeling conventions, we also include a quadratic term for GDP per capita and take the natural $\log$ of both variables.

International trade has also been identified as an important driver of environmental outcomes, with nuanced effects that vary across nations [83, 89-92]. Accordingly, we include a control variable for exports as a percentage of GDP. Nations with larger militaries tend to have lower environmental performance than their counterparts [72, 83, 93], and we control for military expenditures as a percentage of GDP to capture this influence. To capture urbanization, we 
use the percentage of national population living in an urban setting. Finally, because this analysis is focused on the energy intensity of well-being, we use an indicator of the percentage of energy consumption from renewable sources. As with our dependent variable, all data for control variables was accessed via the $d b$ worldbank Stata plug-in for the World Bank's online database [78]. Our merged dataset covers the years 1990-2008. Descriptive statistics for the control and democracy treatment variables are provided in Table 1.

\section{Statistical methods}

\section{Causal inference}

In addition to employing novel indicators of democracy, we also seek to improve causal inference in cross-national studies. Experimental manipulation where cases are randomly assigned to the treatment and control condition is widely considered the "gold standard" of causal inference-that is, randomization produces the strongest evidence of causation. More technically, randomization of treatment status creates a condition called statistical equivalence (alternatively known as "covariate balance"). Covariate balance is a condition in which the treatment and control groups are equivalent on all variables, both unobserved and observed, in terms of descriptive statistics such as the mean or standard deviation. Observational studies, on the other hand, rely on data that does not include randomization of treatment assignment and estimates derived from observational data, such as regression coefficients, cannot be considered strictly causal. Typically, observational studies suffer from selfselection problems whereby characteristics of cases determine their selection into the treatment or control status. This problem is evident in our dataset as democracies differ from non-democracies on a range of variables. A further complication to identifying the causal impact of institutional conditions is rooted in their relative stability. For

Table 1 Descriptive statistics for predictor variables

\begin{tabular}{lllll}
\hline & Mean & Std. dev. & Min & Max \\
\hline Elected executive & 0.436 & 0.496 & 0.000 & 1.000 \\
Elected legislature & 0.926 & 0.263 & 0.000 & 1.000 \\
Political competition & 0.917 & 0.276 & 0.000 & 1.000 \\
Full & 0.416 & 0.493 & 0.000 & 1.000 \\
Military expenditures (\% of GDP) & 0.416 & 0.493 & -11.011 & 104.079 \\
Exports (\% of GDP) & 2.836 & 10.661 & -43.095 & 67.710 \\
Renewable energy consumption & 0.350 & 4.310 & -32.456 & 23.921 \\
(\% Total) & & & & \\
GDP per capita & -0.078 & 0.191 & -1.131 & 1.219 \\
GDP per capital squared & -1.413 & 3.430 & -18.302 & 22.674 \\
Urban population (\% total) & 5.206 & 4.580 & -4.949 & 23.899 \\
\hline Al predis
\end{tabular}

All predictors group-demeaned instance, few countries are apt to change from a nonelected legislature to an elected legislature over several years. This means that we cannot exploit within-country variability in our treatments to untangle a causal estimate of the effect of institutional conditions.

Several techniques rooted in the counterfactual tradition $[94,95]$ have been proposed to address the problem of covariate imbalance. While the specifics of the various methods vary, they are united in that their primary purpose is to take observational data and create covariate balance between treatment and control groups-that is, the goal of many counterfactual methods is to produce an analysis that mimics randomization of treatment assignment as occurs in experimental studies. Propensity score matching is one of the most common, if not the most common, method of addressing the covariate imbalance problem. Propensity score matching involves two steps. In the first step, the researcher implements a selection model (typically using binary logistic or binary probit regression) using treatment status as the dependent variable and variables that explain selection into the treatment or control group as predictors. Then, a probability of treatment (i.e., a propensity score) is calculated for each case, and treatment and control cases with similar propensity scores are matched $[96,97]$.

The propensity score method has several drawbacks. The most significant problem is model dependence. Typically, researchers use a rather ad hoc process to create the selection model, check said model against various diagnostics, and perhaps estimate additional models if diagnostics indicate that the selection model performs poorly. This process results in propensity scores that are sensitive to model specification. Recently, Hainmueller [98] proposed an alternative solution to the problem of covariate imbalance called entropy balancing. When given covariates, entropy balancing implements an algorithm that generates weights that balance sample moments (i.e., means, standard deviations) between treatment and control groups [96]. Thus, entropy balancing is inherently less model dependent than propensity score matching. The balancing weights are somewhat analogous to sampling weights more familiar to most social scientists. However, instead of correcting for the probability of selection, the balancing weights correct for covariate imbalance between the treatment and control groups on the variables entered in the algorithm.

For reasons we discuss further below, we cannot easily combine entropy balancing with many common panel regression estimators and thus cannot use fixed effects to remove within-subject variability. As an alternative, we first panel-demeaned all predictors, which has the effect of removing between-subjects' variability. After panel demeaning, we used the ebalance command in Stata 14 to execute entropy balancing [99]. The entropy balancing algorithm 
successfully balanced all predictors on their first and second sample moments (that is, their means and standard deviations) and generated balancing weights to be used in regression models reported below.

\section{Statistical models}

As noted above, the output of entropy balancing is a weight that corrects for covariate imbalance. Many of the most common panel data estimators-such as the popular GLS estimator used by Stata's xtreg routine-require that weights are constant within panels. However, entropy balancing weights individual observations. In lieu of a more common panel data estimator, we opt for a multi-level generalized linear model (GLM) approach estimated with Stata/IC 14's xtmixed command using maximum likelihood with clustered standard errors. This estimator and general modeling strategy are rooted in the multi-level modeling tradition, also sometimes referred to as mixed models or hierarchical linear models [100, 101]. These models allow intercepts to vary randomly across countries, and in addition to the control variables identified above, we include year fixed effects. For the sake of parsimony, we do not report the results of the year fixed effects in our output tables. ${ }^{3}$ The countries included in our analysis are listed in the "Appendix" section.

\section{Results and discussion}

Table 2 provides results from the multi-level GLM specifications for each treatment variable. First, we consider the models for elected legislatures (model 1). This model suggests that countries with elected legislatures, as opposed to those with non-elected legislatures, do not systematically differ in terms of EIWB. Moving forward to our elected legislature treatment variable, we find that nations with elected legislatures, as opposed to those without, have improved EIWB but this effect is not statistically significant. In model 3 we estimated the effect of political competition. Here, competing political parties appear to increase EIWB but, as with prior models, this effect is not statistically significant. Model 4 tests the effect of a full democracy-defined as the combination of elected executives, elected legislatures, and competitive political partie$\mathrm{s}$-and again we observe a null effect. ${ }^{4}$ These models indicate that, once covariate imbalance is accounted for, democracy nor any of its specific subcomponents drive the energy intensity of well-being.

Overall, our results provide strong evidence that observed differences in the energy intensity of wellbeing across nations have little to do the extent of democratization in those nations. None of the facets of democracy we consider in this paper-elected chief executive, elected legislature, or competitive parties-approach statistical significance and the effects of these variables are small in practical terms. Indeed, even "full" democratization, defined as the combination of an elected executive, elected legislature, and competitive political parties, appears to have no detectable effect on the energy efficiency of well-being. This finding is especially robust because we used entropy balancing to create statistical equivalence. This method is akin to treating institutional conditions as if they were randomly assigned across countries with respect to our predictor variables. Hence, this study provides relatively strong evidence that institutional conditions, in the form of different facets of democracy, have little to no impact on the energy intensity of well-being. Put another way, democracies do not appear to use their energy consumption anymore or less efficiently than non-democracies to improve well-being.

However, economic development, measured by GDP per capita, emerged as a key factor in EIWB. Indeed, GDP per capita and its quadratic transformation were the only consistent predictor across all four model specifications. In all models, growth in GDP per capita reduced EIWB, suggesting that growth in national wealth will facilitate more efficient use of energy to promote well-being.

However, this effect was non-linear in all models. Hence, it seems that income growth beyond a certain point might increase the EIWB. When estimating regression models with quadratic terms, it is important to ascertain the turning point in the relationship-that is, at what point does growth in GDP per capita increase EIWB, given that the quadratic term is statistically significant. Following Plassmann and Khanna [102], we performed the following calculation for each of our models:

$$
\begin{aligned}
\text { Turning point }= & {[(-\beta \log \text { GDP per capita } /} \\
& (-2 \beta \text { logged GDP per capita squared })]
\end{aligned}
$$

Notably, the turning point for all models was at unusually high levels of GDP per capita growth. For instance, for the full democracy model, the turning point for was 9 units of logged GDP, beyond the actual range of the data. Thus, the relationship between economic development and EIWB is more or less linear across a typical range of the data. This finding is in contrast to [42], who report that economic growth might increase the ecological intensity of well-being, using ecological footprints and life expectancy in their ratio. One possible explanation for 
Table 2 Mixed effect models for the energy efficiency of well-being

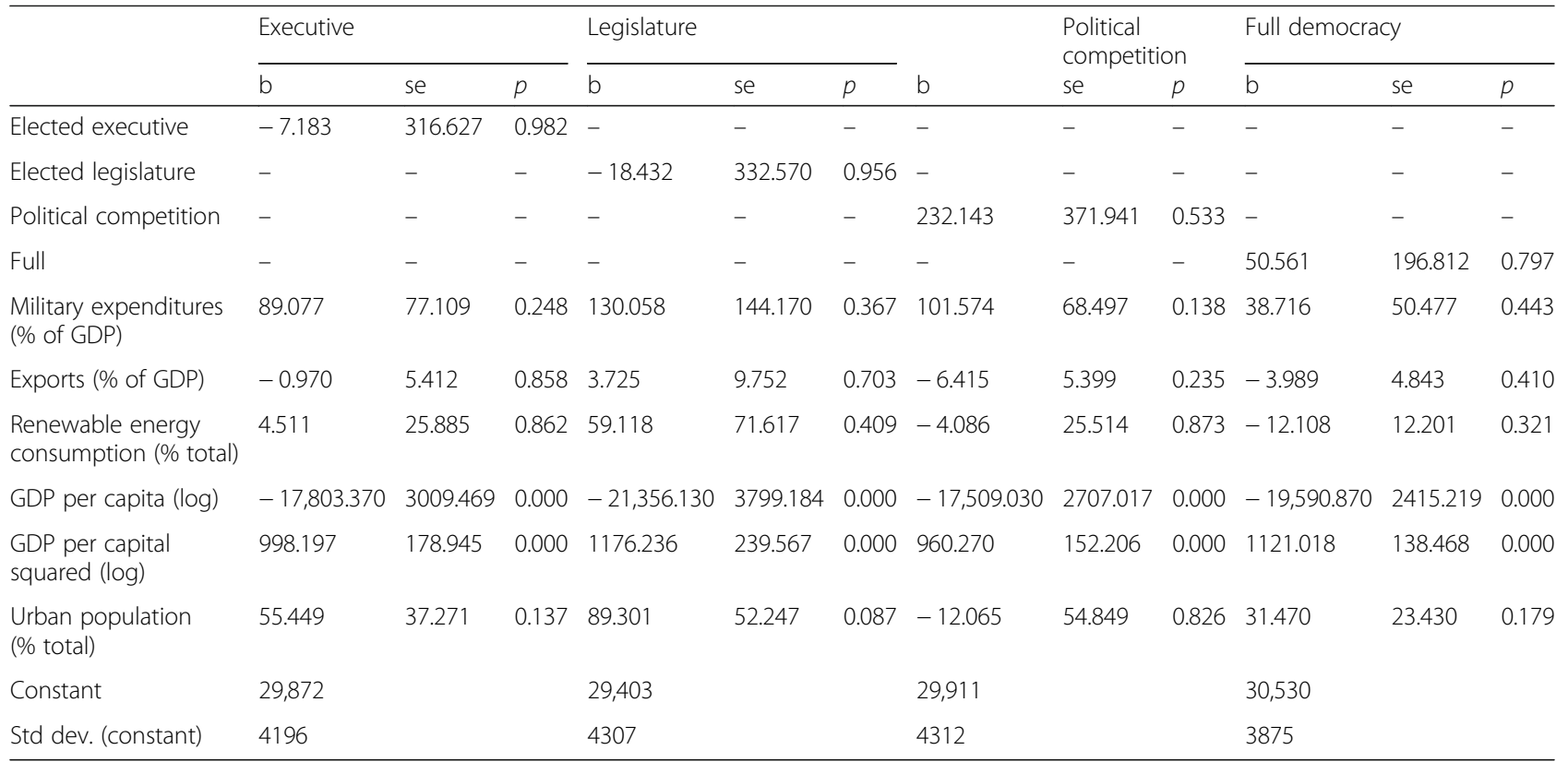

All models include year fixed effects and entropy balancing weights. $n=2150$ observations, 138 countries. All predictors are group-demeaned

these conflicting findings is that economic growth does not increase the energy intensity of well-being, but leads to other changes in production and consumption patterns that have a larger ecological impact. Disentangling the relationship between different indicators of ecological intensity is an important task for future research.

Across all model specifications, the percentage of energy consumption derived from renewable energy did not reach statistical significance and had a substantively small coefficient. The null findings for this variable imply that EIWB is not influenced by the source of energy. Thus, this null effect suggests that countries can increase their usage of renewable energy with no resulting change in the energy intensity of well-being. While renewable energy may not make nations more environmentally efficient, it also does not hinder well-being.

The null findings are somewhat surprising, given that studies have alternatively found that democracy improves or damages environmental performance at the national level. It is possible that our results differ because of methodological considerations-such as the choice of democracy indicator and use of causal inference techniques. Earlier, we noted that democracy might increase environmental degradation because it allows citizens to express their preference for more economic growth and consumption, while others suggest that democracy allows citizens to mobilize to protect the environment. Perhaps both countervailing dynamics are captured via national-level indicators of democracy-future studies could attempt to capture citizen preferences for economic growth vs. environmental quality in varying national contexts.

\section{Conclusion}

Global energy consumption will increase drastically in the coming decades, creating immense environmental stress. Using energy resources more efficiently to improve human well-being while limiting environmental and public health impacts is a significant global development challenge. Hence, it is important to empirically document the factors that drive not only energy consumption and the efficient use of energy to promote human well-being. In this paper, we sought to extend the prior literature on the ecological efficiency of well-being by specifically examining the energy intensity of wellbeing in a sample of nations from 1990 to 2008 with a focus on institutional factors. We argued that, net of controls, the character of a nation's government may affect the efficiency by which said nation uses energy resources to promote well-being. In doing so, we used causal inference methods to isolate the effect of democracy on the energy intensity of well-being. We adopted a multi-faceted understanding of democracy informed by [26]. Initially, we expected that democracies would more effectively use energy consumption to improve wellbeing. However, our results indicated that full democracies fair no better on EIWB and there are no specific components of democracies (i.e., elected executives or legislatures) that impact EIWB. Hence, democratization 
may translate into reduced environmental harm (net of other predictors) but it does not appear that democracies harness their energy consumption more efficiently in the promotion of the well-being of their populations. On the other hand, the null effect of democracy and its subcomponent suggest that democracy will not lead to less efficient energy use, either.

This study is not without limitations. While the entropy balancing method provides stronger causal evidence than more typical methods, we caution that our study does not fully determine if democracy causes (or does not cause) EIWB. More specifically, our models are robust against covariate imbalance on the predictors included in the entropy balancing algorithm but are not necessarily robust against omitted variable bias. Future studies could consider an alternative set of predictors to better understand the factors that explain cross-national variation in EIWB.

\section{Endnotes}

${ }^{1}$ Rao and Baer [40] and Rao and Min [7] argue that "decent" standards of living should include considerations beyond mere subsistence needs such as access to communication technology and refrigeration as well as education and health services, implying the need for infrastructure build-out in developing nations. Unpacking these considerations are beyond this paper, but the authors encourage interested readers to consult their analyses.

${ }^{2} \mathrm{GNI}$ or GDP per capita can be measured in many ways, and popular data sources such as that hosted by the World Bank provide several different measures of economic development. In unreported analyses, we accessed and correlated several measures of GNI and GDP per capita and found that they were all strongly related $(r>.85)$. This suggests that our results are not sensitive to the choice of a particular indicator of economic development.

${ }^{3}$ Some studies (e.g., [103]) have detected significant temporal variability in the relationship between predictors like economic development and the ecological intensity of well-being. We estimated a series of unreported models wherein we removed the year fixed effects and inserted an interaction term between time (in our case, a linear year term) and our treatment variables. These models suggested that the largely null effects reported here are stable across time.

${ }^{4}$ The null effects could exist if our democracy variables were highly collinear with other predictors. We assessed multi-collinearity with variance inflation factors (VIFS), and with the exception of GDP per capita and its quadratic term, the VIFs were all below two, indicating that multicollinearity does not plague our models.

\section{Appendix}

Table 3 Countries included in analysis

\begin{tabular}{|c|c|c|c|}
\hline Albania & Djibouti & South Korea & $\begin{array}{l}\text { Russian } \\
\text { Federation }\end{array}$ \\
\hline Algeria & $\begin{array}{l}\text { Dominican } \\
\text { Rep. }\end{array}$ & Kuwait & Saudi Arabia \\
\hline Angola & Ecuador & Kyrgyz Rep. & Senegal \\
\hline Argentina & $\begin{array}{l}\text { Egypt, Arab } \\
\text { Rep. }\end{array}$ & Latvia & Seychelles \\
\hline Armenia & El Salvador & Lebanon & Singapore \\
\hline Australia & $\begin{array}{l}\text { Equatorial } \\
\text { Guinea }\end{array}$ & Libya & Slovak Republic \\
\hline Austria & Eritrea & Lithuania & Slovenia \\
\hline Azerbaijan & Estonia & Luxembourg & South Africa \\
\hline Bahrain & Fiji & Macedonia & Spain \\
\hline Bangladesh & Finland & Malaysia & Sri Lanka \\
\hline Belarus & France & Malta & Sudan \\
\hline Belgium & Gabon & Mauritius & Swaziland \\
\hline Belize & Gambia, The & Mexico & Sweden \\
\hline Benin & Georgia & Moldova & Switzerland \\
\hline Bolivia & Germany & Mongolia & Syria \\
\hline $\begin{array}{l}\text { Bosnia and } \\
\text { Herzegovina }\end{array}$ & Ghana & Morocco & Tajikistan \\
\hline Botswana & Greece & Mozambique & Tanzania \\
\hline Brazil & Guatemala & Myanmar & Thailand \\
\hline Brunei Darussalam & Guinea-Bissau & Namibia & Togo \\
\hline Bulgaria & Guyana & Nepal & $\begin{array}{l}\text { Trinidad and } \\
\text { Tobago }\end{array}$ \\
\hline Cabo Verde & Haiti & Netherlands & Tunisia \\
\hline Cambodia & Honduras & $\begin{array}{l}\text { New } \\
\text { Zealand }\end{array}$ & Turkey \\
\hline Cameroon & Hungary & Nicaragua & Turkmenistan \\
\hline Canada & India & Niger & Ukraine \\
\hline Chile & Indonesia & Nigeria & $\begin{array}{l}\text { United Arab } \\
\text { Emirates }\end{array}$ \\
\hline China & Iran, Islamic Re & Norway & United Kingdom \\
\hline Colombia & Iraq & Oman & United States \\
\hline Congo, Rep. & Ireland & Pakistan & Uruguay \\
\hline Costa Rica & Israel & Panama & Uzbekistan \\
\hline Cote d'Ivoire & Italy & Paraguay & Venezuela \\
\hline Croatia & Jamaica & Peru & Vietnam \\
\hline Cuba & Japan & Philippines & Yemen \\
\hline Cyprus & Jordan & Poland & Zambia \\
\hline Czech Republic & Kazakhstan & Portugal & Zimbabwe \\
\hline Denmark & Kenya & Qatar & \\
\hline
\end{tabular}

Abbreviations

EIWB: Energy intensity of well-being 


\section{Acknowledgements}

The author thank the editorial staff and anonymous reviewers for their helpful commentary.

\section{Funding}

The author received no funding to conduct this research.

\section{Availability of data and materials}

All data used in this analysis is freely available via the links included in the text and references.

\section{Authors' contributions}

AM wrote the manuscript, gathered the data, and implemented the analysis.

\section{Authors' information}

Department of Human Dimensions of Natural Resources, Colorado State University.

\section{Ethics approval and consent to participate}

This study uses public, aggregated secondary data and is exempt from standard human subjects' ethics approval.

\section{Consent for publication}

The author consents to publication.

\section{Competing interests}

The author declares that he has no competing interests.

\section{Publisher's Note}

Springer Nature remains neutral with regard to jurisdictional claims in published maps and institutional affiliations.

Received: 11 July 2017 Accepted: 17 October 2017

Published online: 01 December 2017

\section{References}

1. Smil V (2010) Energy transitions: history, requirements, prospects. ABC-CLIO, Santa Barbara

2. Smil V (2012) Harvesting the biosphere: What we have taken from nature. MIT Press, Cambridge

3. Fogel RW (1994) Economic growth population theory and physiology: the bearing of long-term processes on the making of economic policy. Am Econ Rev 84(3):369-395

4. Mazur A, Rosa E (1974) Energy and life-style. Science 186:607-610

5. Stern DI (2011) The role of energy in economic growth. Ann N Y Acad Sci 1219:26-51

6. Lamb WF, Rao ND (2015) Human development in a climate-constrained world: what the past says about the future. Glob Environ Chang 33(0):14-22

7. Rao ND, Min J (2017) Decent living standards: material prerequisites for human wellbeing. Soc Indic Res:1-20. doi:10.1007/s11205-017-1650-0

8. Malthus TR (1888) An essay on the principle of population: or, A view of its past and present effects on human happiness. Reeves and Turner, London

9. Jevons WS (1906) The coal question: an inquiry concerning the progress of the nation, and the probable exhaustion of our coal-mines. Macmillan, London

10. Meadows D, Randers J, Meadows D (2004) Limits to growth: the 30-year update. Chelsea Green Publishing, London

11. Ehrlich P (1970) The population bomb. Buccaneer Books, New York

12. Trasande L, Landrigan PJ, Schechter C (2005) Public health and economic consequences of methyl mercury toxicity to the developing brain. Environ Health Perspect. 113(5):590-596

13. Tang D, Li T, Liu JJ et al (2008) Effects of prenatal exposure to coal-burning pollutants on children's development in China. Environ Health Perspect 116:674

14. Hill EL (2012) Unconventional natural gas development and infant health: evidence from Pennsylvania. Charles H Dyson School of Applied Economics and Management Working Paper 12:2013

15. Pickle LW, Gottlieb MS (1980) Pancreatic cancer mortality in Louisiana. Am J Public Health 70:256-259

16. Mehlman MA (2006) Causal relationship from exposure to chemicals in oil refining and chemical industries and malignant melanoma. Ann N Y Acad Sci 1076:822-828
17. Pönkä A (1991) Asthma and low level air pollution in Helsinki. Arch Environ Health 46:262-270

18. Finkelman RB, Orem W, Castranova V et al (2002) Health impacts of coal and coal use: possible solutions. Int J Coal Geol 50:425-443

19. Chen J, Liu G, Kang Y et al (2014) Coal utilization in China: environmental impacts and human health. Environ Geochem Health 36:735-753

20. Dale VH, Efroymson RA, Kline KL (2011) The land use-climate change-energy nexus. Landsc Ecol 26:755-773

21. Ziv G, Baran E, Nam S et al (2012) Trading-off fish biodiversity, food security, and hydropower in the Mekong River basin. Proc Natl Acad Sci 109:5609-5614

22. Devine-Wright P (2009) Rethinking NIMBYism: the role of place attachment and place identity in explaining place-protective action. J Comm Appl Soc Psychol 19:426-441

23. Dietz T, Rosa EA, York R (2009) Environmentally efficient well-being: rethinking sustainability as the relationship between human well-being and environmental impacts. Hum Ecol Rev. 16(1):114-123

24. Jorgenson AK, Alekseyko A, Giedraitis V (2014) Energy consumption, human well-being and economic development in central and eastern European nations: a cautionary tale of sustainability. Energy Policy 66:419-427

25. Sweidan OD, Alwaked AA (2016) Economic development and the energy intensity of human well-being: evidence from the GCC countries. Renew Sust Energ Rev 55:1363-1369

26. Cheibub JA, Gandhi J, Vreeland JR (2010) Democracy and dictatorship revisited. Public Choice 143:67-101

27. Cottrell F (1955) Energy and society: the relation between energy, social changes, and economic development. McGraw-Hill, New York

28. Alam MS, Roychowdhury A, Islam KK, Huq AMZ (1998) A revisited model for the physical quality of life (PQL) as a function of electrical energy consumption. Energy 23:791-801

29. Olsen ME (1992) The energy consumption turnaround and socioeconomic wellbeing in industrial societies in the 1980s. Advances in Hum Ecol 1:197-234

30. Suarez CE (1995) Energy needs for sustainable human development

31. Easterlin, RA (1995) Will raising the incomes of all increase the happiness of all?. J Econ Behav Organ 27(1):35-47.

32. Rosa, EA. 1997. "Cross-national trends in fossil fuel consumption, societal well-being and carbon releases." Environmentally significant consumption: research directions 100-109

33. Pasternak AD (2000) Global energy futures and human development: a framework for analysis. Lawrence Livermore National Laboratory. http://citeseerx.ist.psu.edu/viewdoc/download?doi=10.1.1.587.2237\&rep= rep1\&type=pdf. Accessed 26 Oct 2017

34. Smil V (2005) Energy at the crossroads: global perspectives and uncertainties. MIT press

35. Dias RA, Mattos CR, Balestieri JA (2006) The limits of human development and the use of energy and natural resources. Energy Policy 34:1026-1031

36. Martinez DM, Ebenhack BW (2008) Understanding the role of energy consumption in human development through the use of saturation phenomena. Energy Policy 36:1430-1435

37. Goldemberg J, Johansson TB, Reddy AK, Williams RH (1985) Basic needs and much more with one kilowatt per capita. Ambio 14(4/5):190-200.

38. Spreng D (2005) Distribution of energy consumption and the 2000W/capita target. Energy Policy 33:1905-1911

39. Steinberger JK, Roberts JT (2010) From constraint to sufficiency: the decoupling of energy and carbon from human needs, 1975-2005. Ecol Econ 70:425-433

40. Rao ND, Baer P (2012) Decent living emissions: a conceptual framework. Sustainability 4(4):656-681

41. Dietz T, Rosa EA, York R (2012) Environmentally efficient well-being: is there a Kuznets curve? Appl Geogr 32:21-28

42. Jorgenson AK, Dietz T (2015) Economic growth does not reduce the ecological intensity of human well-being. Sustain Sci 10:149-156

43. Jorgenson AK (2014) Economic development and the carbon intensity of human well-being. Nat Clim Chang 4:186

44. Jorgenson AK (2015) Inequality and the carbon intensity of human wellbeing. J Environ Stud Sci 5:277-282

45. Givens JE (2015) Urbanization, slums, and the carbon intensity of well-being: implications for sustainable development. Hum Ecol Rev 22:107-128

46. Knight KW, Rosa EA (2011) The environmental efficiency of well-being: a cross-national analysis. Soc Sci Res 40:931-949

47. Chambers N, Simmons C, Wackernagel M (2014) Sharing nature's interest: ecological footprints as an indicator of sustainability. Routledge 
48. Jorgenson, AK (2007) The effects of primary sector foreign investment on carbon dioxide emissions from agriculture production in less-developed countries, 1980-99. Int J Comp Sociol 48(1):29-42.

49. Dasgupta P (2001) Human well-being and the natural environment. Oxford University Press

50. Balmford A, Bond W (2005) Trends in the state of nature and their implications for human well-being. Ecol Lett 8:1218-1234

51. Deutsch L, Folke C, Skanberg K (2003) The critical natural capital of ecosystem performance as insurance for human well-being. Ecol Econ 44:205-217

52. Rosa EA, Dietz T (2012) Human drivers of national greenhouse-gas emissions. Nat Clim Chang 2:581

53. Mehlum H, Moene K, Torvik R (2006) Institutions and the resource curse. Econ J 116(508):1-20

54. Bernauer T, Koubi V (2009) Effects of political institutions on air quality. Ecol Econ 68:1355-1365

55. De Mesquita BB, Morrow JD, Siverson RM, Smith A (2002) Political institutions, policy choice and the survival of leaders. Br J Polit Sci 32:559-590

56. Congleton RD (1992) Political institutions and pollution control. Rev Econ Stat 3:412-421.

57. Spaargaren G, Mol AP (1992) Sociology, environment, and modernity: ecological modernization as a theory of social change. Soc Nat Resour 5(4):323-344.

58. Mol AP (2002) Ecological modernization and the global economy. Glob Environ Polit 2:92-115

59. Mol AP (2003) Globalization and environmental reform: the ecological modernization of the global economy. MIT Press

60. Mather AS, Needle CL, Fairbairn J (1998) The human drivers of global land cover change: the case of forests. Hydrol Process 12:1983-1994

61. Midlarsky MI (1998) Democracy and the environment: an empirical assessment. J Peace Res 35:341-361

62. Farzin $\mathrm{YH}$, Bond CA (2006) Democracy and environmental quality. J Dev Econ 81(1):213-235.

63. Ozymy J, Rey D (2013) Wild spaces or polluted places: contentious policies, consensus institutions, and environmental performance in industrialized democracies. Glob Environ Polit 13:81-100

64. De Soysa I, Bailey J, Neumayer E (2012) Free to squander?: democracy and sustainable development, 1975-2000. MIT Press

65. Li Q, Reuveny R (2006) Democracy and environmental degradation. Int Stud Q 50:935-956

66. Kinda SR (2010) Does education really matter for environmental quality?

67. Torras M, Boyce JK (1998) Income, inequality, and pollution: a reassessment of the environmental Kuznets curve. Ecol Econ 25:147-160

68. Harbaugh WT, Levinson A, Wilson DM (2002) Reexamining the empirical evidence for an environmental Kuznets curve. Rev Econ Stat 84:541-551

69. Barrett S, Graddy K (2000) Freedom, growth, and the environment. Environ Dev Econ 5:433-456

70. Shandra JM, McKinney LA, Leckband C, London B (2010) Debt, structural adjustment, and biodiversity loss: a cross-national analysis of threatened mammals and birds. Hum Ecol Rev 17:18-33

71. Jorgenson AK, Burns TJ (2007) Effects of rural and urban population dynamics and national development on deforestation in less-developed countries, 1990-2000. Sociol Inq 77:460-482

72. Jorgenson AK, Burns TJ (2007) The political-economic causes of change in the ecological footprints of nations, 1991-2001: a quantitative investigation. Soc Sci Res 36:834-853

73. Shandra JM, Leckband C, McKinney LA, London B (2009) Ecologically unequal exchange, world polity, and biodiversity loss: a cross-national analysis of threatened mammals. Int J Comp Sociol 50:285-310

74. Shandra JM (2007) Economic dependency, repression, and deforestation: a quantitative, cross-national analysis. Sociol Inq 77:543-571

75. Jorgenson AK, Dick C, Mahutga MC (2007) Foreign investment dependence and the environment: an ecostructural approach. Soc Probl 54:371-394

76. Gallagher KP, Thacker SC (2008) Democracy, income, and environmental quality

77. Povitkina M, Jagers SC, Sjöstedt M, Sundström A (2015) Democracy, development and the marine environment-a global time-series investigation. Ocean Coast Manag 105:25-34

78. Azevedo JP (2016) WBopEndata: stata module to access World Bank databases

79. York R, Rosa EA, Dietz T (2003) Footprints on the earth: the environmental consequences of modernity. Am Sociol Rev 68(2):279-300.

80. Sharma SS (2011) Determinants of carbon dioxide emissions: empirical evidence from 69 countries. Appl Energy 88:376-382
81. Mayer A (2013) Education and the environment: an international study. Int J Sust Dev World 20(6):512-519

82. Mayer A (2017) Will democratization save the climate? An entropy-balanced, random slope study. Int J Sociol 47(2):81-98

83. Jorgenson AK, Clark B (2009) The economy, military, and ecologically unequal exchange relationships in comparative perspective: a panel study of the ecological footprints of nations, 1975-2000. Soc Probl 56:621-646

84. York R, Rosa EA, Dietz T (2003) STIRPAT, IPAT and ImPACT: analytic tools for unpacking the driving forces of environmental impacts. Ecol Econ 46:351-365

85. Dinda S (2004) Environmental Kuznets curve hypothesis: a survey. Ecol Econ 49:431-455

86. Stern DI, Common MS, Barbier EB (1996) Economic growth and environmental degradation: the environmental Kuznets curve and sustainable development. World Dev 24:1151-1160

87. Lindmark M (2002) An EKC-pattern in historical perspective: carbon dioxide emissions, technology, fuel prices and growth in Sweden 1870-1997. Ecol Econ 42:333-347

88. Narayan PK, Narayan S (2010) Carbon dioxide emissions and economic growth: panel data evidence from developing countries. Energy Policy 38:661-666

89. Cole MA (2004) US environmental load displacement: examining consumption, regulations and the role of NAFTA. Ecol Econ 48:439-450

90. Roberts JT, Parks BC (2009) Ecologically unequal exchange, ecological debt, and climate justice: the history and implications of three related ideas for a new social movement. Int J Comp Sociol 50:385-409

91. Steinberger JK, Roberts JT, Peters GP, Baiocchi G (2012) Pathways of human development and carbon emissions embodied in trade. Nat Clim Chang 2(2):81

92. Lamb WF, Steinberger JK, Bows-Larkin A, Peters GP, Roberts JT, Wood FR (2014) Transitions in pathways of human development and carbon emissions. Environ Res Lett 9(1):1-10.

93. Alvarez CH (2016) Militarization and water: a cross-national analysis of militarism and freshwater withdrawals. Environ Soc 2:298-305

94. Morgan SL, Winship C (2014) Counterfactuals and causal inference. Cambridge University Press, New York.

95. Rubin DB (2005) Causal inference using potential outcomes: design, modeling, decisions. J Am Stat Assoc 100:322-331

96. Guo S, Fraser MW (2014) Propensity score analysis: statistical methods and applications. Sage Publications

97. Caliendo M, Kopeinig S (2008) Some practical guidance for the implementation of propensity score matching. J Econ Surv 22:31-72

98. Hainmueller J (2012) Entropy balancing for causal effects: a multivariate reweighting method to produce balanced samples in observational studies. Polit Anal 20:25-46

99. Hainmueller J, Xu Y (2013) Ebalance: a Stata package for entropy balancing. J Stat Software 54(7):1-18

100. Raudenbush SW, Bryk AS (2002) Hierarchical linear models: applications and data analysis methods. Sage

101. Singer JD, Willett JB (2003) Applied longitudinal data analysis: modeling change and event occurrence. Oxford university press

102. Plassmann F, Khanna N (2007) Assessing the precision of turning point estimates in polynomial regression functions. Econ Rev 26:503-528

103. Knight KW (2014) Temporal variation in the relationship between environmental demands and well-being: a panel analysis of developed and less-developed countries. Popul Environ 36(1):32-47

\section{Submit your manuscript to a SpringerOpen ${ }^{\circ}$ journal and benefit from:}

- Convenient online submission

- Rigorous peer review

- Open access: articles freely available online

- High visibility within the field

- Retaining the copyright to your article

Submit your next manuscript at $>$ springeropen.com 